Journal of Transport and Land Use 1:1 (Summer 2008) pp. 13-19

Available at http://jtlu.org

\title{
JTLU
}

\section{Counterpoint: Accessibility and sprawl}

\section{Randall Crane}

University of California, Los Angeles ${ }^{a}$

\section{Introduction}

There is little doubt that Robert Bruegmann did transportation and urban development researchers a great service with his recent work on the history of urban form. He situated contemporary discussions of "sprawl," its problems and many policy responses in well-researched historical context-and he analyzed those responses and that context in substantive, purposeful detail. That he managed to carry this off in a bold, engaging and successfully marketed manner only leaves one all the more envious of the overall package. A real consequence is that it is now more difficult to argue that sprawl is new, peculiarly American, or universally bad, however one might measure sprawl, new, American, or bad. The conventional image of sprawl as little more than a stick figure scapegoat is a lot less credible, and perhaps even nearer the end of its useful rhetorical life.

Bruegmann's essay for this journal volume summarizes the backbone of that story, found in longer form in Sprawl: A Compact History (2005), and then applies it to this journal's domain, land use/transportation problems and remedies. The boldness, ferocity, and mercilessness of his attacks on sprawl critics and "Smart Growth" advocates alike apparently encouraged the editors to ask that I, an innocent reviewer of the original submission, prepare a counterpoint. To what, I replied? To his points, they answered. But his book cites my research in support of its transportation arguments, I replied back, with which I agree and for which I am grateful. You're a professional, the editors instructed; do your best.

This will be brief.

Bruegmann's thesis certainly has strengths as well as weaknesses. As mentioned, it is rich in historical antecedents to the decentralized urban forms popularly disparaged as modern sprawl, particularly as explained by the twin, relentless forces of rising real incomes and falling real transportation costs. He also argues that the converse, high density, can cause more traffic problems than it solves. Sprawl happens, in other

acrane@ucla.edu 
words. In its cold determinism, it is nigh universal and relatively unyielding to policy or prayers.

Rather than stop there, at testable evidence of reasonable explanations of the empirics, the author goes on to forcefully proclaim many of sprawl's features as merits and, by extension, the counterproductive nature of anti-sprawl policies, such as smart growth.

Bruegmann's normative narrative has two fundamental problems: The costs of sprawl are substantially more nuanced than represented, and Smart Growth is inadequately characterized. Each argument may still be useful in policy debates but they are also essentially speculative, and thus do much to undermine his larger lessons about the causes and consequences of sprawl for transportation/land use policy.

I elaborate slightly in what follows, by first proposing how to think about sprawl as a problem, and then how to think about Smart Growth as an appropriate response. The conclusion returns to accessibility and transportation policy.

\section{The costs of sprawl}

What is wrong with sprawl? Start with what makes any problem a problem. To leave things complex enough to usefully frame the issues, yet plain enough to not lose them in the muddle, I restrict this essay to three kinds of classic urban development problems: market failure, regulatory failure, and participatory failure. ${ }^{1}$

The first is the traditional, textbook notion of when and where private markets lead to social inefficiencies (Pigou 1920). Familiar examples are noncompetitive markets, where individual suppliers have excess market power, externalities/public goods, where private consumption has collective impacts not mediated by markets, such as in Hardin's (1968) "tragedy of the commons," and collectively undesirable inequities. Regulatory failures are the public sector counterpart to market failures, where governments go beyond correcting market failures to cause inefficiencies of their own (Wolf 1993). That is, where public actions make markets perform worse rather than better. Participatory failures refer instead to where the give and take of decision-making is somehow inadequate for other reasons, such as by criteria for inclusiveness, communication, or representation (Habermas 1962; Fainstein 2008).

Where does sprawl fit? Brueckner (2000) famously argued that sprawl is only a resource problem to the extent it results from market failures. He identifies the undervaluation of open space, "excess" traffic congestion, and the underpriced environmental costs of automobility as three clear examples. Sprawl-induced spatial inequities would go here as well, though that evidence may be more complex than thought (Pendall

${ }^{1}$ Using these three models partly addresses the concern of Small (2000), who suggests we focus on the individual problems often associated with sprawl, rather than try to contain them all together in a single, comprehensive, yet ill-fitting framework. 
and Carruthers 2003; Wheeler 2006). ${ }^{2}$ Levine (2005) emphasizes regulatory failure, where the myopic self-interest of decentralized land use authorities can serve to restrict the supply of higher density, moderate income, and less car-dependent communities. Putnam (2001), Healy (1997), and a slew of others before and since, discuss how the manner in which fragmented communities are organized, collaborate, and make governance and planning decisions, can hurt their individual and collective performances, measured any number of ways.

Bruegmann glosses over all of these sorts of social costs, if he mentions them at all. (He does allow that low density development may have environmental costs, such as greenhouse gas emissions, which should be addressed directly, via environmental instruments, rather than indirectly with urban design.) My guess is that emphasizing the benefits of decentralized growth, at the expense of attention to its attendant costs, was a conscious decision aimed at highlighting the other, less commonly discussed side of things. Still, those problems remain and are necessary considerations in any normative assessment of what sprawl represents. Ignoring them, in an erstwhile comprehensive profile of a broadly defined development type, amounts to dismissing them, weakening his big picture, high road argument that sprawl is oversimplified and misunderstood.

\section{Smart Growth in three easy pieces}

If sprawl has these problems, what remedies follow? Again, Bruegmann's position is that since sprawl is mostly virtuous and virtually unavoidable, policy interventions intended to neutralize it are counterproductive and ineffective, or worse. His example is Smart Growth, which he describes as anti-car, pro high-density, and sweetly sentimental.

But Smart Growth has considerably more content than that, if you look close. I personally prefer my definition to his, yet admit one great underlying challenge in this debate is the fickle and thus feckless vogue of the term's meaning. It can signify most any "right-minded" development strategy in popular and scholarly application, other than complete planning anarchy. Even if some on either side of the question find that flexibility an advantage, this almost boundless ambiguity suggests the impossible burden placed on the poor phrase; how could it possible deliver?

To assist, I offer my working definition: Smart Growth is actually three separate planning initiatives, sometimes bundled together and sometimes not (Crane 2008). In order of their visibility, the first is what urban planners would call "urban planning;" in other words, along the lines of thoughtful, forward-looking, comprehensive, integrated land use and infrastructure planning. This can be enough of a novelty to laypeople,

\footnotetext{
${ }^{2}$ Indeed, Glaeser and Kahn (2004), "suggest that the primary social problem associated with sprawl is the fact that some people are left behind because they do not earn enough to afford the cars that this form of living requires," a point I return to in the conclusion.
} 
who tend to find the idea of looking ahead attractive in principle but are unaware of a profession dedicated to that purpose, that it explains a large share of the public interest in Smart Growth.

The second initiative emphasizes specific technical tools, of the sort that might be called "compact development best practices." It includes the things planners talk about most when they talk about Smart Growth, namely, higher densities, greater mixed use, urban growth boundaries, and improved pedestrian- and transit-orientation. This is what the Sierra Club, the Natural Resources Defense Council, the American Planning Association, the Congress for the New Urbanism, and other environmental constituencies tend to focus on. It is also what Bruegmann takes issue with.

The last Smart Growth component features process, or "deal making," ignored by Bruegmann and most popular and published analyses, or changes in how land use deals are mediated. The difference between this and the traditional process model — where land owners and land regulators parley over project placement and details - is that the environmental community is brought into the game much earlier, largely due to their effectiveness in using citizen-enforced environmental regulations (e.g., the Endangered Species Act, the Clean Air and Water Acts, the California Environmental Quality Act) to delay or block projects. Thus Smart Growth is more participatory than the alternative, though by how much is not at all clear. It certainly is not open to all affected parties.

Does Smart Growth, as defined here, make things worse or better? In part a response depends on which leg of the 3-legged Smart Growth stool one refers to, and on the case at hand. More to the point of this essay, Bruegmann's complaint is strongest where he suggests that urban design strategies aimed at reducing car use can go awry, or at least under perform. On the one hand, to the extent greater automobility delivers net benefits, any policies limiting these—such as building fewer roads or raising the cash or time costs of driving - may well leave travelers and their communities worse off. On the other, even where cars impose net social costs, it is far from clear which urban design policies can influentially reduce traffic congestion or VMT, or improve accessibility, or for whom (e.g., Boarnet and Crane 2001). The closing section below discusses this further.

But Smart Growth is also about planning process, governance, and participation, each with the potential to deliver more accountable, egalitarian and responsive development outcomes. How effectively this approach can or will address the gamut of regulatory and participatory failures associated with fragmented, decentralized metropolitan growth is impossible to say in the abstract. Neither can it be dismissed out of hand as counterproductive.

Thus, Bruegmann's broadsides against Smart Growth make one fair point: Naïvely crude anti-car programs, whether effective or not, are naïve and crude. My counterpoint is that this is scarcely a novel, systematic, or especially useful critique. Smart 
growth is mostly significant as a branding tactic for somewhat more inclusive, negotiated, and environmental planning elements than in your mother's day. In general, those are best evaluated case by case, element by element. As to the compact development aspirations of specific Smart Growth plans, the jury is still out on what they can or should accomplish. Overstating that uncertainty, as Bruegmann does with some verve, may not move these discussions along any further than understating it, as unduly optimistic pop planners often do with at least as much heart.

\section{Bruegmann on accessibility}

Has suburbanization improved or worsened travel access? As with sprawl and Smart Growth, the language of accessibility can be confusing and pliable, depending on one's purpose. That said, there is growing agreement among transportation scholars that access refers specifically to the purpose of travel, while mobility simply represents the ease of getting from point $A$ to some other point $B$ (e.g., Levinson and Krizek 2005). In that view, access is about being places and doing things-it is about the value of obtaining the opportunities at $B$-where mobility is about the cost of doing so. Access is a commodity; mobility is its unit price.

When Bruegmann argues that Smart Growth, and related policy schemes aimed at curbing the excesses of sprawl, will reduce accessibility, I understand him to mean that anti-car policies may reduce both mobility, by raising the cost of car use, and accessibility, by restricting the travel options cars often provide.

These are important points, and I mostly agree. Many critics of the social costs of automobiles neglect to consider the marked benefits of mobility or, more troublesome still, how those benefits and costs are distributed. These critiques lately take the form of promoting accessibility as a transportation performance criterion over the traditional one of mobility. There is disagreement over whether more of one can be had without less of the other-if there is an accessibility/mobility efficiency frontier, so to speak - but it is easy to imagine where less of both might have significant negative consequences (Crane, van Hengel, and Schweitzer 2008). Further, even where concerted transportation/land use strategies successfully promote access, those disadvantaged by higher car costs may not be those benefiting from greater accessibility to particular places. Either way, Bruegmann fails to dissect these differences in a rigorous manner. This is not to say doing so is necessary, just that the issues are otherwise confounded.

Put another way, though suburbanization is commonly blamed, implicitly or explicitly, for worsening the circumstances of the urban poor, it is hard to imagine how policies that in some manner limit their automobility, and thus access to work and other amenities, could possibly help. Yet identifying the winners and losers under different urban form/transportation scenarios, a topic Bruegmann also neglects, is woefully understudied. 
If Bruegmann oversimplifies both sprawl and its critics in order to focus our attention on his central thesis that suburbanization is underappreciated, his point is well taken. However, cutting those corners invites his own primary objection, that logic and evidence which does not neatly fit the story is being purposefully disregarded. It is no small irony that a more even-handed and nuanced treatment would get him where he wants to go that much faster and safer.

\section{References}

Boarnet, M. and R. Crane (2001). Travel by design: The influence of urban form on travel. Oxford.

Brueckner, J. (2000). Urban sprawl: Diagnosis and remedies. International Regional Science Review, 23.

Bruegmann, R. (2005). Sprawl: A compact history. Chicago.

- (2008). Sprawl and accessibility. Journal of Transport and Land Use. In this issue.

Crane, R. (2008). Smart growth in three easy pieces: A deconstruction. UCLA working paper.

Crane, R., D. van Hengel, and L. Schweitzer (2008). A note on supply versus demand in travel access. UCLA working paper.

Fainstein, S. (2008). Planning and the just city. In: e. a. Peter Marcuse, ed., Searching for the just city. Taylor and Francis.

Glaeser, E. and M. Kahn (2004). Sprawl and urban growth. In: V. Henderson and J.-F. Thisse, eds., The handbook of regional and urban economics, volume 4 . North Holland.

Habermas, J. (1962, translated 1991). The structural transformation of the public sphere: An inquiry into a category of bourgeois society. MIT Press.

Hardin, G. (1968). The tragedy of the commons. Science, 162.

Healey, P. (1997). Collaborative planning: Shaping places in fragmented societies. MacMillan.

Levine, J. (2005). Zoned out: Regulation, markets, and choices in transportation and metropolitan land use. Resources for the Future.

Levinson, D. and K. Krizek, eds. (2005). Access to destinations. Elsevier.

Pendall, R. and J. Carruthers (2003). Does density exacerbate income segregation? evidence from U.S. metropolitan areas, 1980 to 2000. Housing Policy Debate, 14: 541-589.

Pigou, A. (1920). The economics of welfare. MacMillan.

Putnam, S. (2001). Bowling alone: The collapse and revival of American community. Simon \& Schuster.

Small, K. (2000). Urban sprawl: A non-diagnosis of real problems. In: Metropolitan development patterns, pp. 26-29. Lincoln Institute of Land Policy. 
Wheeler, C. (2006). Urban decentralization and income inequality: Is sprawl associated with rising income segregation across neighborhoods. Federal Reserve Bank of St. Louis working paper \#2006-037A.

Wolf, C. (1993). Markets or governments: Choosing between imperfect alternatives. MIT Press. 